\title{
Uma perspectiva da Clínica Ampliada: as práticas da Psicologia na Assistência Social
}

\author{
Ana Paula da Silva Dettmann, Elizabeth Maria Andrade Aragão, Lilian Rose Margotto \\ Universidade Federal do Espírito Santo, Vitória, ES, Brasil
}

\begin{abstract}
Resumo
O cenário contemporâneo da Política Pública de Assistência Social é apresentado através da Psicologia Institucional, que direciona a uma certa visão da Psicologia sobre a Política de Assistência Social. O objetivo da presente pesquisa foi investigar a visão dos psicólogos sobre essa política e as práticas que eles próprios desenvolvem. Os depoimentos de onze psicólogos atuantes na Política e no Fórum de Trabalhadores do SUAS, investigados pela História Oral, apresentaram as práticas da Psicologia na Assistência Social, tendo sido destacada a questão do poder entremeado às estratégias biopolíticas de controle e resistências, que ora reproduzem normatizações, ora produzem linhas de fugas. Ainda, ressaltou a perspectiva da Clínica Ampliada com as possibilidades de transformação dos sujeitos e da sociedade, a partir de uma visão clínica e crítica da Psicologia e da Politica de Assistência Social.
\end{abstract}

Palavras-chaves: Psicologia; Assistência Social/SUAS; Clínica Ampliada.

\section{A perspective Expanded Clinic: Psycology's practices in Social Service}

\begin{abstract}
The present days concerning Public Social Assistance Policy are revealed by Institutional Psychology, which leads to a specific point of view from Psychology to the Social Assistance Policy. The aim of this research was to investigate the views of psychologists on the policy and practices that they themselves develop. The testimonies of eleven psychologists working in the policy and Workers Forum, investigated by the Oral History, presented the psychology practices in social assistance and the issue of power highlights, intermixed with biopolitics strategies of control and resistance, which sometimes reproduce policies, sometimes produce escape from reality. Also stressed the perspective of Expanded Clinic with the possibilities of transformation of individuals and society, from a clinical and critical view of Psychology and Social Assistance Policy.
\end{abstract}

Keywords: Psychology; Social Service/SUAS; Expanded Clinic.

O presente trabalho apresenta a interlocução da Psicologia e Política e o cenário contemporâneo da Política Pública de Assistência Social, analisado por meio da Psicologia Institucional e da História Oral, pretendeu ampliar a discussão da Psicologia, a partir de uma visão clínica e crítica sobre o seu trabalho nas Políticas Públicas. Tal Clínica é entendida como uma intervenção política, que envolve na prática as possibilidades de transformação do sujeito e da sociedade, sendo ressaltada como estratégia de potencializar a vida quando ela não se conforma com a sobrevida e encontra linhas de fuga, que pulsam no aspecto da coletividade e da solidariedade.

Nessa perspectiva ampliada da Clínica, que ultrapassa muito além do indivíduo, e compreende as questões coletivas e políticas, observou-se as relações e jogos de poder que circulam nas políticas de gestão e controle da vida, assim como as práticas de resistências que se constroem, cotidianamente, nesses espaços. Sem a pretensão de tratar de todos os elementos ou mesmo de abarcar os vários questionamentos e possíveis campos de pesquisa em sua totalidade, as discussões foram pensadas sobre as formas como estão constituídas as relações de psicólogos como agentes políticos em uma complexidade histórica, política e social.

\footnotetext{
^Endereço para correspondência: Universidade Federal do Espírito Santo, Centro de Ciencias Humanas e Naturais, Departamento de Psicologia. Av. Fernando Ferrari s/n - CEMUNI VI - Sala 13. Goiabeiras - Vitoria, ES - Brasil.CEP: 29060-900.E-mail: apdettmann@yahoo.com.br, baragao@me.com, lilian_margotto@yahoo.com.br
}

Para delimitar um recorte da amplitude do tema, o debate aqui se fez no âmbito da Assistência Social, mais especificamente, da Psicologia como profissão vinculada a essa política. Tal política foi privilegiada como campo de coleta de depoimentos, contudo, as observações/problemáticas discutidas são encontradas em outros campos da política pública atual. Políticas Públicas de Educação, Saúde, Segurança Pública, entre outras, são apresentadas, em inúmeras pesquisas, sobre os seus cenários atuais. Compreendem-se, assim, as problemáticas discutidas nessa pesquisa, e nos outros campos, como uma inter-relação direta do sistema econômico-político vigente com as práticas de suas referidas Políticas.

Nesse sentido, o objetivo foi pesquisar a atuação dos psicólogos nas Políticas Públicas, especificamente na Política de Assistência Social, na perspectiva de entender as práticas que desenvolvem, suas concepções acerca dos conceitos da Política, alguns aspectos do cotidiano de trabalho, embrenhados em jogos de poder e nas práticas de resistência.

A metodologia utilizada foi pautada na História Oral, sendo utilizada com o intuito de aproximação com o cotidiano de trabalho, com a história da política, os padrões sociais, a história das comunidades, das instituições e das experiências (ALBERTI, V., 2004). A 
opção por essa metodologia não foi meramente estética ou científica, mas foi fundamentalmente política, como nos aponta o autor:

Contar histórias, articular historicamente o passado, posicionar-se em relação ao passado e fazer um diagnóstico do presente não são atitudes que se diferenciam nas discussões benjaminianas e, talvez aí, se elaborem as maiores contribuições para um estudo das narratividades nas sociedades contemporâneas (FERREIRA, 2011, p. 127).

Utilizamo-nos de Benjamin, uma vez que a questão da narratividade trazida pelo autor proporciona a figura do contador de histórias. O narrador é, exatamente, o portador do acervo de toda uma vida, não só da própria experiência, mas também em grande parte da experiência alheia (BENJAMIN, 1994). Os nossos entrevistados nada mais foram do que contadores de histórias. Onze (11) psicólogos, servidores públicos, que atuavam na Assistência Social no Espírito Santo e participavam do Fórum Estadual dos Trabalhadores do SUAS; sendo esses os critérios que os elegeram como sujeitos da pesquisa, além da disponibilidade pessoal. Tal Fórum é um espaço permanente de representação dos trabalhadores e deliberação da política, aquele pretende se caracterizar como um espaço de discussão profissional. Tal espaço foi instituído a partir de uma mobilização nacional, que direcionou agentes inseridos nas Políticas Sociais no Estado do Espírito Santo a se organizarem, com objetivo de articularem e mobilizarem ações no âmbito da Assistência Social, resguardados por um Fórum Nacional com as mesmas pautas. Enquanto pesquisa qualitativa foi baseada em depoimentos orais; desse modo, as entrevistas, que aconteceram no ano de 2012, tinham um roteiro semiestruturado a ser vencido, com temas extremamente amplos, a fim de propiciar depoimentos e relatos pessoais sobre formação, experiências profissionais, Política, Psicologia e Fórum dos Trabalhadores. Os relatos orais foram gravados, transcritos e analisados a partir das temáticas afins.

Esses psicólogos narraram suas histórias que não se separam de modo algum do período histórico em que vivem, e do contexto político que envolve formação e trabalho na atualidade. Essa abordagem discursiva considera que os sujeitos estiveram inseridos em um contexto histórico social e envolvidos por determinadas condições, e, que as formações e as práticas não foram apresentadas com um percurso único presente nelas mesmas, mas sim foram construídas mediante as relações de poder que estão instituídas bem como aos jogos institucionais que instituem novas práticas (ORLANDI, 1996, 2003; PÊCHEUX, 1990).

\section{As perspectivas para a Clínica Ampliada: o campo das Políticas Públicas}

Nessas análises, os pontos que foram privilegiados nos relatos eram elementos constituintes da formação e exercício da Psicologia e da vida política, relações nas quais se observaram as políticas de gestão da vida - de controle e de resistências.

Fractal, Rev. Psicol., v. 28 - n. 3, p. 362-369, 2016
A discussão da Política evocou uma pluralidade de ideias, remetendo às primeiras concepções da Política, que se estruturaram como modo de organização social, baseada na pluralidade dos homens, na relação entre homens, na convivência e organização para certas coisas em comum que seriam essenciais e fundamentais para a sobrevivência, produção e relação (ARENDT, 1997, 2004). Mas as análises se detiveram nas mais recentes concepções modernas que foram engendradas, a partir do século XVII, em uma nova lógica econômica e social, com transformações profundas nos modos da produção do trabalho, da administração pública e da gestão política. $\mathrm{O}$ que submeteu as sociedades contemporâneas, as Políticas Públicas e as suas formas de governo, a uma análise centrada no capitalismo e no seu desenvolvimento, como sistema imanente, que se reencontra sempre com os próprios limites em uma escala cada vez mais ampliada (DELEUZE, 1992, p. 212).

Essas relações políticas são entremeadas em jogos de força e poder. Entendendo que o poder é um exercício e só existe nas relações de força, em uma situação estratégica e em um dado momento (FOUCAULT, 1985). O poder que passou então a ser exercido sobre a vida, o biopoder, são formas de gerir, administrar e maximizar a vida, constituindo um mecanismo que leva em conta a regulação da população, como natalidade, mortalidade, saúde pública, habitação (FOUCAULT, 2008). Tais fenômenos foram abarcados pela biopolítica, exercida como uma política de regulamentação da vida, sobre o corpo social, sobre a população, em seus fenômenos coletivos e políticos, sobre as massas. A biopolítica é traduzida em uma tecnologia de controle da população em dimensões globais com efeitos regulamentadores e protecionistas da vida.

Esse novo modo de governar se dá pela Governamentalidade, que se define em termos de um conjunto de estratégias que tem por alvo a população, por forma principal de saber a economia política e por instrumentos os dispositivos de segurança (FOUCAULT, 1984b, p. 171). É o modo que o Governo assume a forma de dirigir a conduta dos indivíduos ou dos grupos, agindo sobre as possibilidades de ação do outro, na perspectiva de estruturar o campo de ação dos indivíduos (FOUCAULT, 1995 , p. 244). É nessa perspectiva, que os governos empregam instrumentos de controle econômico e de saberes no interior de uma série de aparelhos específicos (FOUCAULT, 2000). Sendo através de um controle contínuo implantado nas formas sutis de educação, sanção e tratamento na chamada Sociedade de Controle (DELEUZE, 1992).

As ações do Estado são mais amplas e difusas, não se vinculando mais ao domínio totalizador ou a proteção essencial à sobrevivência. Ele se figura como protetor dos direitos do cidadão, em que a família e o indivíduo devem ter suas vidas protegidas para que possam investir em uma ascensão na qualidade da vida disponibilizada pelo sistema de consumo (BENEVIDES DE BARROS, 2002). Em suas formas tão múltiplas de relações, o Estado, embora não mais centralize os jogos do poder, atrai-nos e captura-nos 
como se as questões públicas estivessem concentradas no seu interior. São governamentalizadas, elaboradas, racionalizadas, centralizadas na forma das instituições do Estado (BENEVIDES DE BARROS; PASSOS, 2005).

Os mecanismos do Estado, dos modos de Governo e do Capital, produzem uma gama de informações, serviços, desejos. São subjetividades produzidas pela biopolítica nesse processo de consumo social, responsabilizando individualmente a cada um pelo trabalho/estudo que o permitirá ascender socialmente. A subjetividade não se refere às concepções de identidade, de estrutura psíquica ou de personalidade, mas traz o sentido da produção das formas de se relacionar, dos afetos construídos, dos modos de vida (MACHADO, 1999).

Assim, as políticas sociais e de segurança se configuram a partir de um "caráter humanitário de intervenções políticas que visam incentivar, proteger, estimular e administrar" a vida das pessoas, como um novo modo de o Estado gerir o cuidado da vida (DUARTE, 2006, p. 50). Apresentam técnicas de instituições abertas e atendimentos domiciliares já surgidas há tempos e que se atualizam nas diretrizes das políticas públicas contemporâneas como direitos e acabam por integrar os mais novos mecanismos de controle. As políticas estão associadas às determinações das ciências da vida, de um modo geral, biomédicas, humanas e sociais.

As ciências da vida partilhavam as preocupações teóricas e práticas de ordem psicológica junto com os outros campos disciplinares: a Medicina, a Pedagogia, a Filosofia. E, ao longo do processo histórico, a Psicologia foi então constituída a partir dessa visão de mundo burguês e de homem liberal, que consolidou processos de naturalização junto com os ideais dominantes da época.

Desse modo, a Psicologia nasceu com essa vertente positivista, como um saber preditivo e diagnóstico, tendo como principal preocupação no âmbito dos estudos a sua colocação como ciência, com a neutralidade, como base para entendimento da criminologia, da loucura, da colocação do homem no local de trabalho, visando à adaptação e ao ajustamento tanto na área da escola quanto dos institutos psicométricos (ALBERTI, S., 1999; BARAÚNA, 1999; BOCK; FURTADO; TEIXEIRA, 1999; CATHARINO, 1999; COIMBRA, 1999; GONÇALVES, 2003; JACÓ-VILELA，1999; KEIDE; JACÓ-VILELA, 1999; MANCEBO, 1999; PEREIRA; PEREIRA NETO, 2003; ROSAS, 2010; SOARES, 2010).

Com tal caráter neutro e diagnóstico, a Psicologia se fez presente nas políticas públicas e sociais: escolas, empresas, instituições de recuperação, situações grupais, como um instrumento a serviço do controle social e da adaptação dos indivíduos e com a função de produzir conhecimentos sobre os comportamentos humanos, vinculada à emissão de laudos e diagnósticos, além do atendimento clínico individual (GONÇALVES, 2003).

Somente a partir da década de 1970, a Psicologia iniciou uma fase de questionamentos sobre a visão de homem que a sustentava e sobre a própria atuação profissional do psicólogo. E, só ao final da década de
1980, que os psicólogos se perguntaram sobre sua responsabilidade diante do contexto social, a partir dos movimentos sociais da década de 1980 que trouxeram à cena novas questões, como o declínio da ditadura militar e da redemocratização na história do Brasil. Assim, a Psicologia se focou em desnaturalizar as demandas produzidas pelo sistema econômico-social e propor intervenções a partir do entendimento a produção histórica e social das subjetividades (COIMBRA et al., 2000). E, então, nos anos 1990, deparou-se com a tarefa de imiscuir-se com as políticas sociais sob outro olhar e foi inserida nas Políticas Públicas, inicialmente na saúde e nas questões sociais que envolvem a violência, concorrendo para a construção de outros caminhos e exercendo seu dever ético de contribuir para a transformação da sociedade.

A despeito do contexto repressor, esses movimentos sociais que aconteceram no país alcançaram avanços e conquistas sociais e políticas importantes para o país, a partir da mobilização da sociedade brasileira em prol da promulgação de uma nova ordem social e transformações em termos de políticas sociais traduzida na nova Constituição (BENEVIDES DE BARROS; PASSOS, 2005).

A ideia da nova Política Social instaurada com a Constituição Federal era romper com os resquícios do assistencialismo e do clientelismo advindos das protoformas da constituição do Serviço Social, que se davam entre ações de repressão e caridade paralelas às leis sociais para pobres do Estado e outros poderes, como a igreja (IAMAMOTO; CARVALHO, 2001). Partindo de ações sociais pautadas em benesses, cada gestão local deveria organizar seu município, em torno da construção de centros de referências, que pudessem refletir a Assistência Social, como direito constitucional e promover autonomia e protagonismo dos cidadãos, com princípios de fortalecer indivíduos e famílias, a partir dos seus contextos socioeconômicos.

Porém, desse avanço, em termos de mobilização social e conquistas legais, o Brasil entrou na era neoliberal, com movimentos globalizantes que já vinham acontecendo em outros países com a abertura do mercado nacional para a economia global logo no primeiro mandato presidencial efetivamente escolhido pelo povo após a redemocratização e a promulgação da nova Constituição. As políticas sociais deixaram o caráter constitucional universal permanente para se tornarem políticas econômicas seletivas e emergenciais, muitas vezes compensatórias, temporárias e focadas na pobreza.

A Assistência Social que, por sua vez, em seu processo histórico de constituição foi marcada pelo assistencialismo, muitas vezes foi utilizada com esse viés, perpetuando práticas de caridade e benefícios eventuais. A continuidade dessas ações se perpetua, por vezes, dentro dos programas políticos de gestores.

Tal política é discutida emaranhada nessas redes de produção de subjetividades e desejos. A legislação construída se apresenta como expressão política das lutas 
e das captações do sistema. A sua formulação é vinculada às estratégias capitalísticas, com os seus instrumentos de controle da vida e, em contrapartida, nos movimentos de desconstrução e construção de outros modos de viver. Isso traduz a noção da produção de subjetividade na cartografia subjetiva de áreas que seguem padrões semelhantes de constituição da vanguarda capitalista (GUATTARI; ROLNIK, 1999). Os mecanismos de controle, sutilmente pensados nessa lógica, são também apresentados na política. Traduzem-se, em termos de instrumentos de trabalho, na distribuição de atendimento por profissionais conforme territorialização pela contagem de números de famílias e indivíduos, no corte de atendimento relativo às cifras de ganhos financeiros, o controle dos índices de qualidade de vida e toda uma lógica de esquadrinhamento da vida.

Nesse campo, também, a Psicologia se posicionou em problematizar as formas de construção da subjetividade, dos modos de governar, de gerir a vida, pautada em uma postura ética-estética-política. Ética como pensamento que avalia os acontecimentos potencializadores ou não de vida; estética como criação, articulando pensamento, ação e sensibilidade; e política como a responsabilização ante aos afetos produzidos, sendo construídos nas ações (GUATTARI, 1992).

A partir desse posicionamento político é que se fizeram possíveis as transformações nas dadas relações de poder. Como o outro termo das relações, as resistências foram construídas nos entremeios da política. As resistências são as relações estabelecidas no coletivo que transformam os sujeitos e criam as linhas de fuga, sendo constituídas pelas lutas que se fazem em nome da vida, ao galgar por novos caminhos e por novos modos de existência. As resistências não se configuram em uma tomada de poder ou metas a serem alcançadas, mas fazem parte de todo o processo histórico desdobrados em modos contraditórios, aleatórios e imprevisíveis nas redes nas quais se movimentam o poder, o controle e o posicionamento de luta.

É exatamente a tomada dessa potência da vida, a biopotência, que se forja a biopolítica em uma inversão do termo foucaultiano, como apontado por autores contemporâneos (PELBART, 2009; AGAMBEM, 2002; NEGRI; HARDT, 2000, LAZARATTO, 2002). É a vida como coletivo, cooperação social, afetação, desejo, inteligência, que se refere a ocupar, preencher e inventar os espaços-tempos desse cotidiano (LAZZARATO, 2002). Essa produção biopolítica de relações e formas sociais transforma-se em formas colaborativas de trabalho, quando se faz possível a inversão do poder sobre a vida para a potência da vida (HARDT; NEGRI, 2005).

Essa potência produz estilos de existência e modos de vida que exprimem uma cooperação coletiva, o que constitui a multidão, quando se pode manifestar legitimamente um mundo de igualdade e liberdade em uma sociedade global democrática aberta e inclusiva. É uma multiplicidade de todas as diferenças singulares, a multidão se apresenta como a alternativa viva dentro da lógica de controle capitalístico da ordem econômica e social mundialmente colocada na contemporaneidade (HARDT; NEGRI, 2005).

\section{A Clínica Ampliada: uma perspectiva no percurso da Psicologia}

Essa volta pela biopolítica do entendimento dos mecanismos de uma política de controle da vida, para uma aposta na vida como potência, é que afirmam os filósofos contemporâneos, os psicólogos anônimos do cotidiano, os personagens das políticas públicas contemporâneas.

Uma aposta afirmada pelos profissionais, que, em suas narrativas, ao resistirem às forças das relações de poder buscavam uma potente construção de prática cotidiana. A construção dessa prática do psicólogo na Política Pública foi pensada no sentido de problematizar os processos de subjetivação instituídos e marcados pelo capitalismo, os contextos sociais e desejos dos indivíduos, construídos e constituídos em dadas situações, tempos e espaços, que são produzidos e produtores de realidades, pela reprodução e invenção de diversos modos de existir; atravessados por desejos e afetos. A partir dos depoimentos dos psicólogos entrevistados tonouse possível dimensionar essa afetação pelo trabalho vivenciado, explicitado em falas, tais como: "Porque está na pele, entendeu? Eu vivi intensamente mesmo esse trabalho" (Psicólogo entrevistado 9).

Os afetos apareceram nos relatos como ações que tendem a diminuir a potência de vida, amortecer, reduzir ao mínimo, acalmar, amansar, controlar, mortificar e são entendidos como atributos que de sobremodo já são cristalizados nas práticas políticas; contudo, também apareceram afetos que podem potencializar a vida ao máximo e se definiram mais por suas linhas de fugas e encontros que traçam o limite do pensamento e do movimento (DELEUZE, 2002). Os tais desejos estão em movimentos, possibilitando um grau de abertura para a vida, que cada um permite a cada momento (ROLNIK, 1989).

Apresentados pelos psicólogos, os discursos demonstraram aquilo que mortifica, mas o que também possibilita criar, inventar e reinventar.

A gente já sabe dizer assim: sabe com quem você tá falando? A gente já sabe com alguma outra palavra indicar quem a gente já sabe que conhece do assunto. A gente já sabe acalmar um morador quando aquilo deveria estar ali e não está... E nessa falinha mansa, às vezes, a gente amansa. A gente já sabe mortificar mesmo (Psicólogo entrevistado 11).

Você não precisa aprender mil e uma dinâmicas, mil e um testes, mil e uma formas prontas de atuar. Você tem que produzir seus próprios instrumentos. Então, isso eu aprendi muito com a formação, com o ensino e com a extensão principalmente: isso de criar instrumentos para o seu trabalho (Psicólogo entrevistado 10). 
Embrenhados à Política nessas relações tecidas nas gestões dos modos de vida, tanto no que diz ao controle quanto a produção de subjetividade, a Psicologia tornouse eminentemente política e a Clínica a sua forma e expressão política.

Em oposição às subjetividades ajustadas, homogeinizadas e assujeitadas, sabemos que o desejo também pode ser revolucionário. Portanto, acreditamos numa indissociabilidade entre clínica e política e reconhecemos outras interfaces como com a filosofia; com as ciências minoritárias, com a arte, com a ética/estética e, portanto, buscamos destacar na intervenção clínica os componentes ético-políticos que atuam na produção subjetiva, entendendo que a economia política e a economia subjetiva são uma mesma coisa. Isso equivale a dizer que definir a clínica em sua relação com os processos de produção de subjetividade implica-nos com a análise crítica das formas instituídas - tornadas hegemônicas, comprometendo-nos politicamente de maneira inexorável (MOURÃO; JORGE; FRANCISCO, 2002, p. 54).

A Clínica, enquanto prática da Psicologia por excelência, ocupou também uma nova forma política, onde são problematizadas as relações de forças e estratégias de gestão e investimento da potencialização da vida, tendo em vista o seu posicionamento ante os efeitos produzidos pelas ações.

A Clínica também é Política. Politica também tem ideologia, e ideologia ela está ai em volta de você, te absorve e você a põe para fora todo momento. Isso também é política. (Psicólogo entrevistado 1).

É nas entrelinhas das relações que a intervenção da clínica se inclina, deriva, desvia de um ponto estabelecido, quando se propõe a descontruir aquilo que é sofrimento para dar lugar a criação de outros modos de existência e estilos de vida (NEVES; JOSEPSHON, 2001, p. 105). É pelo entendimento da origem grega da palavra que sua concepção conceitual mais profunda pode ser apreendida:

Derivada do grego klinikos ("que concerne ao leito"; de klíne, "leito, repouso"; de klíno "inclinar, dobrar"). Mais do que essa atitude de acolhimento de quem demanda tratamento, entendemos o ato clínico como a produção de um desvio (clinamen), na acepção que dá a essa palavra a filosofia atomista de Epicuro (1965). Esse conceito da filosofia grega designa o desvio que permite aos átomos, ao caírem no vazio em virtude de seu peso e de sua velocidade, se chocarem articulando-se na composição das coisas. Essa cosmogonia epicurista atribui a esses pequenos movimentos de desvio a potência de geração do mundo. É na afirmação desse desvio, do clinamen, portanto, que a clínica se faz (BENEVIDES DE BARROS; PASSOS, 2001, p. 93).

Nas histórias de quem contou essas vivências do cotidiano da Psicologia na Política Pública, obteve-se o entendimento nos seguintes termos:

A minha compreensão de Clínica é de uma Clínica Ampliada, uma clínica bem diferente desse chavão da visão que se tem hoje de um modo geral... A política de Assistência realmente não prevê uma prática clínica se for conceber uma clínica em um modelo individualizante e descontextualizada. E, na verdade, não cabe não só na Assistência, não cabe na Saúde, não cabe em lugar nenhum, enfim, não cabe talvez nem em um consultório particular que seja... A gente sabe que tem coisas que a gente tem capacidade técnica para intervir, para fazer uma escuta diferenciada, para fazer uma intervenção que às vezes outros profissionais não têm (Psicólogo entrevistado 10).

Desse modo, a Clínica como atuação política se faz necessariamente no campo social, onde produz e reproduz ideologias e práticas, não sendo possível separar as múltiplas manifestações sociais da vida da produção de subjetividades e desejos nas estratégias biopolíticas da contemporaneidade. Nessa perspectiva em favor da vida, a Psicologia assumiu uma responsabilidade social e uma prática ética pela constituição de outros modos de vida não assujeitados a um controle ou uma gestão despotencializadora da vida.

Pessoalmente, eu acredito que a função do psicólogo no SUAS seja exatamente problematizar esses processos de produção de subjetividade, as formas que estão implantadas, implementadas, de viver, de governar. Então é problematizar isso! A função do psicólogo tem essa função de problematizar, independente da abordagem teórica, a função dele é problematizar, então se ele está em uma política pública de Assistência Social, a função é problematizar os modos de viver, os modos de governar naquele território (Psicólogo entrevistado 5).

Além da necessidade de ultrapassar o imaginário do papel diagnóstico e terapêutico ou, ainda, do fetiche do conhecimento e especialismo psi, paralelamente, é preciso reafirmar o conhecimento específico e as contribuições reais da categoria em meio às estratégias políticas de gestão da vida.

Dessa forma, quando tomamos a clínica como eminentemente política, ou seja, como problematização de valores, sentidos fixos, universais e como possibilidades de conexão com as práticas de "invenção de si", é que podemos afirmar o que produzimos no campo da formação "Psi", bem como no campo da intervenção em instituiçõesestabelecimentos, como clínica. Ou seja, a crítica como clínica (NEVES; JOSEPHSON, 2001, p.105).

Os modos de intervenção se atualizam nos encontros, momentos e relações, que acolhem o outro que traz o sofrimento, lamento e queixas e facilitam transformações nos indivíduos, nos coletivos e nas próprias subjetividades, produzindo potência, e compondo vidas e produzindo sentidos, não dominantes e nem totalizantes.

Os encontros da clínica partem de uma construção coletiva, necessariamente não individualizante, independentemente se o atendimento realizado é estruturado sob modelo individual ou em grupos de trabalho; não sendo reduzida aos atendimentos individuais ou mesmo às práticas coletivas padronizadas e individualizantes que veem o sujeito em uma dimensão pessoal. Acontecem nos mais variados espaços e contextos, dependendo cada vez menos de uma estrutura delimitada a um setting psicológico do consultório com divã ou dos testes diagnósticos.

Fractal, Rev. Psicol., v. 28 - n. 3, p. 362-369, 2016 
A partir de perguntas, da intervenção, de um olhar, de um gesto, a partir do silêncio, não tem receita, não tem padrão, o que a gente pode é utilizar algumas ferramentas conceituais, algumas técnicas, ai pode variar. No atendimento grupal, eu posso fazer essa intervenção; no atendimento individual, eu posso fazer essa intervenção; em uma oficina; em um curso, eu posso fazer essa intervenção; em uma visita domiciliar, várias técnicas; em uma reunião na comunidade; em todos esses espaços eu posso problematizar. O importante é talvez em que direção, quais princípios, de onde parte, aonde quer chegar. Qual compromisso, qual implicação se tem com isso, não tem receita, o campo de inventividade é muito amplo (Psicólogo entrevistado 5).

São esses movimentos de análise da própria prática que contribuem para a construção de políticas públicas efetivas e resolutivas das reais demandas da sociedade e de uma coletividade constituída de relações mais éticas e solidárias. É quando se torna possível uma transformação nas relações de poder das políticas cotidianas de gestão da vida para uma política nesses termos que entendemos. As resistências a uma interiorização do biopoder e a constituição do plano coletivo, onde de fato se constroem políticas públicas (BENEVIDES DE BARROS; PASSOS, 2005).

A atuação clínica na intervenção do psicólogo nos espaços e demandas legítimos das realidades contemporâneas constrói modalidades diferentes do trabalho do psicólogo, que objetivam refletir sentidos, participar da produção dos modos de existência, atuar na formação e transformação das subjetividades e produzir encontros potencializadores de vida.

Esses processos de trabalho acontecem em meio ao contexto do sucateamento das políticas públicas e da precarização do serviço público, perpassando burocracia administrativa e arquitetônica dos espaços públicos. Assim, as práticas que foram apresentadas compreendiam alternativas políticas e pedagógicas, com encaminhamentos efetivos, em que se fazia necessário tensionar as estruturas endurecidas e romper com práticas institucionalizadas em que não circulam a potência das comunidades que estão circunscritas nas margens das políticas públicas.

Contudo, o desafio da Psicologia se esbarra em dividir essas perspectivas potencializadoras do trabalho com a faceta tarefista, automática, mecanizada e quantitativa, priorizados os dados e a mídia, que exige do trabalhador a produtividade e, muitas vezes, a condição de um mero encaminhador, ou o faz sucumbir às práticas antiéticas instaladas na gestão ou sucumbir ao adoecimento do trabalhador.

Você tem dois trabalhos, o trabalho que você está recebendo para fazer, que chega como mandato social da sua profissão, que está no edital para você executar; e, um outro trabalho, que é de manter as condições dignas de trabalho, transformar as condições de trabalho para você continuar trabalhando (Psicólogo entrevistado 11).
Ressaltou-se como importante na execução desse trabalho o potencializar a vida e as vinculações possíveis a esta, as discussões para além do que circunda a questão administrativa ou financeira. Foi afirmado um compromisso ético traduzido em uma responsabilidade social de não permitir reduzir essas discussões a políticas estatais ou estratégias de governo, visto que discursa sobre uma política da vida, uma utopia ativa e realizável, aberta às singularidades e à multidão, como a possibilidade de expressão da potência de uma multiplicidade. "Ah, eu acredito muito nisso! Eu acho que a nossa utopia ativa vai sempre estar se transformando, eu acho que sempre a gente vai ter que repensar e rever [...]" (Psicólogo entrevistado 9).

Utopia ativa nos remete ao sentido da ética de um poder constituinte, que alega uma forma política de desutopia e que recusa a utopia alienada e linear (NEGRI, 2002). Lutas constituídas pela multidão para a constituição das Políticas Públicas, do acesso ao serviço público, do acesso igualitário aos direitos, lutas embrenhadas permanentemente no cotidiano, nos trabalhos, na Clínica.

Isso conforma outra clínica, clínica da invenção e da experimentação de práticas que são sempre sociais. $O$ indivíduo e o social aqui só aparecem como formas, expressão de fluxos que se cortam incessantemente, fluxos coletivos, devires sempre outros. A clínica que daí se depreende não se opõe ao social nem o complementa, já que mutação subjetiva e social são apenas formas com que os infinitos processos de diferença podem se expressar (BENEVIDES DE BARROS, 2002, p. 136).

A Psicologia assumiu esse compromisso social como agente político e agente transformador da realidade social, afirmando o lugar da sua contribuição tal como a problematização dos processos de subjetivação e da construção dos modos de vida nas comunidades. A perspectiva dos espaços coletivos é sobremodo importante componente da sua prática contemporânea, onde se podem construir vínculos, subjetividades e modos de vida, ideais das redes de solidariedade e processos de autogestão da comunidade. É nela que se vislumbram as reflexões da Clínica, os movimentos de embates das correlações de forças, resistências e a constituição de agentes sociais e redes paralelas de solidariedade.

\section{Referências}

ALBERTI, S. História da Psicologia no Brasil: origens nacionais. In: JACÓ-VILELA, A. M.; JABUR, F.; RODRIGUES, H. B. C. (Org.). Clio-psyché: histórias da psicologia no Brasil. Rio de Janeiro: UERJ, NAPE, 1999. Disponível em: <http://www. cliopsyche.uerj.br/livros/clio1/historiadapsicologia. htm>. Acesso em: 5 nov. 2011.

ALBERTI, V. Ouvir e contar: textos em história oral. Rio de Janeiro: FGV, 2004.

AGAMBEM, G. Homo sacer: o poder soberano e a vida nua. Tradução de Henrique Búrigo. Belo Horizonte, UFMG, 2002. v. 1.

ARENDT, H. A condição humana. Tradução de Roberto Raposo. 8. ed. Rio de Janeiro: Forense Universitária, 1997. 
ARENDT, H. O que é Politica? Tradução de Reinaldo Guarany. 5. ed. Rio de Janeiro: Bertrand Brasil, 2004.

BARAÚNA, L. M. P. B. Da História da Psicologia para uma História na Psicologia. In: JACÓ-VILELA, A. M.; JABUR, F.; RODRIGUES, H. B. C. (Org.). Clio-psyché: histórias da psicologia no Brasil. Rio de Janeiro: UERJ, NAPE, 1999. Disponível em: <http://www.cliopsyche.uerj.br/livros/clio1/ dahistoriadapsicologiapara.htm >. Acesso em: 5 nov. 2011.

BENEVIDES DE BARROS, R. Clínica e social: polaridades que se opõem/complementam ou falsa dicotomia. In: RAUTER, C.; PASSOS, E.; BENEVIDES DE BARROS, R. (Org.). Clínica e política: subjetividade e violação dos direitos humanos. Equipe Clínico-Grupal, Grupo Tortura Nunca Mais - RJ. Rio de Janeiro: Instituto Franco Basaglia/ TeCorá, 2002. p. 123-139.

BENEVIDES DE BARROS, R.; PASSOS, E. Clínica e biopolítica na experiência do contemporâneo. Psicologia Clínica, v. 13, n. 1, p. 89-100, 2001.

BENEVIDES DE BARROS, R. PASSOS, E. A humanização como dimensão pública das políticas de saúde. Ciência e Saúde Coletiva, Rio de Janeiro, v. 10, n. 3, jul.-set. 2005. p. 561- 571 Cross ${ }^{\text {Ref. }}$

BENJAMIN, W. Sobre o conceito da História. Tradução de Sergio Paulo Rouanet. In: ___ Obras escolhidas: magia, técnica, arte e política. 7. ed. São Paulo: Brasiliense, 1994. v. 1, p. 222-253.

BOCK, A. M. M.; FURTADO, O.; TEIXEIRA, M. L. T. Psicologias: uma introdução ao estudo da psicologia. São Paulo: Saraiva, 1999.

CATHARINO, T. R. Fragmentos da História da Psicologia no Brasil - algumas notações sobre teoria e prática. In: JACÓ-VILELA, A. M.; JABUR, F.; RODRIGUES, H. B. C. (Org.). Clio-psyché: histórias da psicologia no Brasil. Rio de Janeiro: UERJ, NAPE, 1999. Disponível em: <http://www. cliopsyche.uerj.br/livros/clio1/fragmentosdahistoria. htm>. Aceso em: 5 nov. 2011.

COIMBRA, C. M. B. Práticas "Psi" no Brasil do "Milagre": algumas de suas produções. In: JACÓ-VILELA, A. M.; JABUR, F.; RODRIGUES, H. B. C. (Org.). Clio-psyché: histórias da psicologia no Brasil. Rio de Janeiro: UERJ, NAPE, 1999. Disponível em: <http://www.cliopsyche.uerj.br/ livros/clio1/praticaspsinobrasildomilagre.htm>. Acesso em: 05 nov. 2011

COIMBRA, C. M. B. et al. Intervenão clínica quanto à violação dos Direitos Humanos: por uma prática desnaturalizadora na teoria, na ética, na política. In: RAUTER, C.; PASSOS, E.; BENEVIDES DE BARROS, R. (Org.). Clínica e política: subjetividade e violação dos direitos humanos. Equipe ClínicoGrupal, Grupo Tortura Nunca Mais - RJ. Rio de Janeiro: Instituto Franco Basaglia/ TeCorá. 2002. p. 113-121.

DELeUZE, G. Conversações. Tradução de Peter Pal Pelbart. São Paulo: Editora 34,1992.

DELEUZE, G. Espinosa: filosofia prática. São Paulo: Escuta, 2002.

DUARTE, A. M. Biopolítica e resistência: o legado de Michel Foucault. In: RAGO, M.; VEIGA-NETO, A. (Org.). Figuras de Foucault. Belo Horizonte: Autêntica, 2006. v. 1, p. 45-56.
FERREIRA, M. S. Walter Benjamin e a questão das narratividades. Mnemosine, Rio de Janeiro, v. 7, n. 2, p. 121133, 2011. Disponível em: <http://www.mnemosine.com.br/ ojs/index.php/mnemosine/article/view/233/pdf_218>. Acesso em: 22 ago. 2013.

FOUCAULT, M. A Governamentabilidade. In: MACHADO, R. (Org.). Microfísica do Poder. 8. ed. Rio de Janeiro: Graal, 1984b. p. 163-174

FOUCAULT, M. A história da sexualidade: a vontade de saber. Tradução de Maria Thereza da Costa Albuquerque e J. A. Guilhon Albuquerque. 7. ed. Rio de Janeiro: Graal, 1985. v. 1.

FOUCAULT, M. O sujeito e o poder. In: HUBERT; DREYFUS; RABINOW. Michel Foucault, uma trajetória filosófica: para além do estruturalismo e da hermenêutica. Tradução de Vera Porto Carrero e Gilda Gomes Carneiro. Rio de Janeiro: Forense Universitária, 1995. p. 231-249.

FOUCAULT, M. Em defesa da sociedade: Curso no Collège de France. Tradução de. Maria Ermantina Galvão. São Paulo: Martins Fontes, 2000. Coleção Tópicos.

FOUCAULT, M. Segurança, território e população. Curso no Collège de France. Tradução de Eduardo Brandão. São Paulo: Martins Fontes, 2008. Coleção Tópicos.

GONÇALVES, M. G. M. Psicologia Sócio-Histórica e Políticas Públicas: a dimensão subjetiva de fenômenos sociais. 2003. Tese (Doutorado) - Pontifícia Universidade Católica de São Paulo, São Paulo, 2003.

GUATTARI, F. Caosmose: um novo paradigma estético. Rio de Janeiro: Ed. 34, 1992.

GUATTARI, F.; ROLNIK, S. Micropolitica: cartografias do desejo. Petrópolis, RJ: Vozes, 1999.

HARDT, M.; NEGRI, A. Multidão: guerra e democracia na era do Império. Tradução de Clovis Marques. Rio de Janeiro: Record, 2005.

IAMAMOTO, M. V.; CARVALHO, R. Relações sociais e serviço social no Brasil: esboço de uma interpretação históricametodologica. São Paulo: Cortez, 2001.

JACÓ-VILELA, A. M. Psicologia: um saber sem memória? In: JACÓ-VILELA, A. M.; JABUR, F.; RODRIGUES, H. B. C. (Org.). Clio-psyché: histórias da psicologia no Brasil. Rio de Janeiro: UERJ, NAPE, 1999. Disponível em: <http://www. cliopsyche.uerj.br/livros/clio1/umsabersemmemoria. htm>. Aceso em 05 nov. 2011.

KEIDE, R.; JACÓ-VILELA, A. M. "Mens in corpore": o positivismo e o discurso psicológico do século XIX no Brasil. In: JACÓ-VILELA, A. M.; JABUR, F.; RODRIGUES, H. B. C. (Org.). Clio-psyché: histórias da psicologia no Brasil. Rio de Janeiro: UERJ, NAPE, 1999. Disponível em: <http://www. cliopsyche.uerj.br/livros/clio1/mensincorpore.htm>. Acesso em: 5 nov. 2011.

LAZARATTO, M. Puissances de l'invention. Paris, Les Empêcheurs de penser em rond, 2002.

MACHADO, L. A. D. Subjetividades contemporâneas. In: BARROS, M. E. B. (Org.). Psicologia: questões contemporâneas. Vitória: EDUFES, 1999. p. 231-247. 
MANCEBO, D. Formação em Psicologia: gênese e primeiros desenvolvimentos. In: JACÓ-VILELA, A. M.; JABUR, F; RODRIGUES, H. B. C. (Org.). Clio-psyché: histórias da psicologia no Brasil. Rio de Janeiro: UERJ, NAPE, 1999. Disponível em: <http:/www.cliopsyche.uerj.br/livros/ clio1/formacaoempsicologia.htm>. Acesso em: 5 nov. 2011.

MOURÃO, J. C.; JORGE, M. A.; FRANCISCO, S. A. Violência organizada, impunidade e silenciamento. In: RAUTER, C.; PASSOS, E.; BENEVIDES DE BARROS, R.(Org.). Clínica e política: subjetividade e violação dos direitos humanos. Equipe Clínico-Grupal, Grupo Tortura Nunca Mais - RJ. Rio de Janeiro: Instituto Franco Basaglia/ TeCorá. 2002. p. 51-58.

NEGRI, A. O poder constituinte: ensaio sobre as alternativas da modernidade. Tradução Adriano Pilatti. Rio de Janeiro: DP\&A, 2002.

NEGRI, A.; HARDT, M. Império. Rio de Janeiro: Record, 2000 .

NEVES, C. A. B.; JOSEPHSON, S. C. A crítica como clínica. In: MACHADO, L. D.; LAVRADOR, M. C. C.; BARROS, M. E. B. (Org.). Texturas da Psicologia: subjetividade e política no contemporâneo. São Paulo: Casa do Psicólogo, 2001. p. 99108.

ORLANDI, E. P. Interpretação: autoria, leitura e efeitos do trabalho simbólico. Petrópolis, RJ: Vozes, 1996.

ORLANDI, E. P. Análise de discurso: princípios e procedimentos. 5. ed. Campinas, SP: Pontes, 2003.

PÊCHEUX, M. O discurso: estrutura ou acontecimento. Tradução de Eni Pulcinelli Orlandi. Campinas, SP: Pontes, 1990.

PELBART, P. P. Vida capital: ensaios de biopolítica. São Paulo: Iluminiras, 2009.

PEREIRA, F. M.; PEREIRA NETO, A. O psicólogo no Brasil: notas sobre seu processo de profissionalização. Psicologia em Estudo, Maringá, v. 8, n. 2, p. 19-27, jul.-dez. 2003. Cross ${ }^{\text {Ref. }}$

ROLNIK, S. Cartografia sentimental: transformações contemporâneas do desejo. São Paulo: Estação Liberdade, 1989.

ROSAS, P. S. O dilema da Psicologia Contemporânea. Revista Psicologia Ciência e Profissão, Brasília, v. 30, n. esp., p. 43-90, dez. 2010. Disponível em: $<$ http://www.scielo.br/scielo.php?script=sci arttext\&pid=S1414-98932010000500003>. Acesso em: 22 set. 2013.

SOARES, A. R. A Psicologia no Brasil. Psicologia Ciência e Profissão, Brasília, v. 30, n. esp., p. 10-41, dez. 2010. Disponível em: $\quad<$ http://www.scielo.br/scielo.php?script=sci arttext\&pid=S1414-98932010000500002\&lng=en\&nrm =iso\&tlng=pt>. Acesso em: 12 ago. 2013.

Recebido em: 13 de outubro de 2013

Aceito em: 1 de dezembro de 2015 